\title{
Acrocomia aculeata prevents toxicogenetic damage caused by the antitumor agent cyclophosphamide
}

\author{
M.F. Magosso ${ }^{1,2}$, P.C. Carvalho ${ }^{1,2}$, B.U.C. Shneider ${ }^{1,2}$, L.R. Pessatto ${ }^{1,3}$, \\ J.R. Pesarini ${ }^{1,2}$, P.V.B. Silva ${ }^{4}$, W.A. Correa ${ }^{4}$, C.A.L. Kassuya ${ }^{4}$, \\ R.M. Muzzi ${ }^{4}$ and R.J. Oliveira ${ }^{1,2,3}$ \\ ${ }^{1}$ Centro de Estudos em Células Tronco, Terapia Celular e Genética Toxicológica, \\ Hospital Universitário "Maria Aparecida Pedrossian”, \\ Empresa Brasileira de Serviços Hospitalares, Campo Grande, MS, Brasil \\ ${ }^{2}$ Programa de Pós-Graduação em Saúde e Desenvolvimento na Região \\ Centro-Oeste, Faculdade de Medicina "Dr. Hélio Mandetta", \\ Universidade Federal de Mato Grosso do Sul, Campo Grande, MS, Brasil \\ ${ }^{3}$ Programa de Mestrado em Farmácia, Centro de Ciências Biológicas e da Saúde, \\ Universidade Federal de Mato Grosso do Sul, Campo Grande, MS, Brasil \\ ${ }^{4}$ Programa de Pós-Graduação em Ciência e Tecnologia Ambiental, \\ Universidade Federal da Grande Dourados, Dourados, MS, Brasil \\ Corresponding author: R.J. Oliveira \\ E-mail: rodrigo.oliveira@ufms.br \\ Genet. Mol. Res. 15 (2): gmr.15027816 \\ Received October 9, 2015 \\ Accepted December 8, 2015 \\ Published May 6, 2016 \\ DOI http://dx.doi.org/10.4238/gmr.15027816
}

\begin{abstract}
Acrocomia aculeata is a plant rich in antioxidant compounds. Studies suggest that this plant has anti-inflammatory, antidiabetic, and diuretic potential. We assessed the antigenotoxic, antimutagenic, immunomodulation, and apoptotic potentials of A. aculeata alone and in combination with an antitumor agent, cyclophosphamide. Swiss male mice $(\mathrm{N}=140)$ were used. The animals were divided into 14 experimental groups as follows: a negative group, a positive group (100 mg/kg cyclophosphamide), groups that only
\end{abstract}


received the oil extracted from the almond (AO) and from the pulp (PO) of A. aculeata at doses of 3,15, and $30 \mathrm{mg} / \mathrm{kg}$, and the associated treatment groups (oils combined with cyclophosphamide) involving pretreatment, simultaneous, and post-treatment protocols. Data suggest that both oils were chemopreventive at all doses, based on the tested protocols. The highest damage reduction percentages, observed for $\mathrm{AO}$ and $\mathrm{PO}$ were 88.19 and $90.03 \%$, respectively, for the comet assay and 69.73 and $70.93 \%$, respectively, for the micronucleus assay. Both AO and PO demonstrated immunomodulatory activity. The oils reduced the capacity of cyclophosphamide to trigger apoptosis in the liver, spleen, and kidney cells. These results suggest that $A$. aculeate $\mathrm{AO}$ and $\mathrm{PO}$ can be classified as a functional food and also enrich other functional foods and nutraceuticals with chemopreventive features. However, they are not appropriate sources for chemotherapeutic adjuvants, in particular for those used in combination with cyclophosphamide.

Key words: Chemoprevention; Bioantimutagenesis; Functional food; Nutraceutical; Macaúba

\section{INTRODUCTION}

The need for compounds to prevent, cure, or treat cancer is increasing, as this disease is a leading cause of death worldwide, second only to cardiovascular diseases (Xie et al., 2013). Ideally, new anticancer agents should exhibit greater specificity and selectivity for tumor cells and induce few side effects (Navarro et al., 2014).

Carcinogenesis may be related to the occurrence of toxicogenetic damage (Mantovani et al., 2008), which could be prevented through the use of nutraceuticals (Bachur et al., 2007) with chemopreventive properties. Such preventive effects might be achieved through the consumption of diets enriched with compounds that are able to reduce the occurrence of genotoxic and/or mutagenic damage (Maluf and Erdtmann, 2003), as the aim of chemoprevention is to prevent, arrest, or reverse either the initial phase of carcinogenesis or the progression of neoplastic cells to malignancy (Baek et al., 2009).

High levels of bioactive compounds are found in plants, many of which have been tested for chemopreventive properties (Mantovani et al., 2008). The list of tested plants includes Acrocomia aculeata, a plant native to South and Central America with demonstrated medicinal (Traesel et al., 2014, 2015) and nutraceutical (Lescano et al., 2015) properties.

A. aculeata is popularly known in Brazil as macaubeiro, bacaiúva, bocaiúva, cocode-catarro, coco-de-espinho, imbocaiá, macaíba, macaiúva, macaúba, macujá, mocujá, and umbocaiúva (Lorenzi et al., 2006). This palm tree is widely distributed across the Brazilian Cerrado, especially in the States of Mato Grosso do Sul, São Paulo, and Minas Gerais, but it is also found in Paraná, Pará, Paraíba, and Pernambuco (Lanes et al., 2015).

Folk medicine uses the pulp of the fruit as a laxative and the oil as an analgesic. When mixed with macerated drupes, the oil is also used to treat respiratory illnesses (Lorenzi et al., 2006). According to Lescano et al. (2015), the pulp oil exhibits anti-inflammatory and diuretic activities. The roots of $A$. aculeata are used by indigenous peoples in Mexico to treat 
diabetes (Sosnowska and Balslev, 2008) and there are descriptions of cosmetic uses for skin hydration and rejuvenation (Lima et al., 2003) because of the antioxidative properties of the plant (Coimbra and Jorge, 2011).

As antioxidants are one relevant type of chemopreventive agent (Sies, 1993), the present study assessed the ability of the oils extracted from A. aculeata almond and pulp to prevent toxic genetic damage by the antitumor agent cyclophosphamide. We also investigated immunomodulation and apoptotic effects of the oils.

\section{MATERIAL AND METHODS}

\section{Plant collection and identification}

Pulp and almond oil were prepared from ripe fruits harvested between March 2010 and February 2011 from plants growing on the sides of the Dourados-Panambizinho highway in Alto Café, Maracaju district, Mato Grosso do Sul, at latitude 21 ${ }^{\circ} 36^{\prime} 52^{\prime \prime}$ South, longitude $55^{\circ} 10^{\prime} 06^{\prime \prime}$ West and an altitude of $384 \mathrm{~m}$.

\section{Oil production}

The fruits were rinsed, peeled, scarified, and dried in a convection oven at $50^{\circ} \mathrm{C}$ for $2 \mathrm{~h}$. Next, the almond and dry pulp fragments were ground and stored under refrigeration at $7{ }^{\circ} \mathrm{C}$.

Each dried sample $(500 \mathrm{~g}$ ) was combined with $1 \mathrm{~L}$ hexane. The mixtures were transferred to 2000-mL Büchner flasks and left to rest, it protected from light for 7 days. The samples were then filtered and concentrated in a rotary evaporator at $57^{\circ} \mathrm{C}$ (Oetterer et al., 2006).

The oils, hereafter referred to as the almond oil (AO) and pulp oil (PO), were stored under refrigeration at $4{ }^{\circ} \mathrm{C}$ until use. Determination of the acid values, transesterification, and characterization of methyl monoesters have been accomplished by Traesel et al. (2014).

\section{Chemical agents}

The chemotherapeutic agent cyclophosphamide (Ítaca Laboratórios - Fosfaseron ${ }^{\circledR}$, REG. M.S. No. 1.2603.0056.002-1; Batch 063020, Brazil), an indirect alkylating agent, was used as a positive control to induce DNA damage. Cyclophosphamide was prepared in normal saline $(0.9 \% \mathrm{NaCl}), \mathrm{pH} 7.4$, and applied in a single dose of $100 \mathrm{mg}$ per $\mathrm{kg}$ body weight (bw) via intraperitoneal (ip) injection (Fedel-Miyasato et al., 2014a).

The oils (AO and PO) were diluted in 4\% Tween and $1 \%$ ethanol and administered at doses of 3,15 , and $30 \mathrm{mg} / \mathrm{kg}$ (bw) via oral gavage ( $p o$ ).

\section{Animals}

A total of 140 sexually mature male Swiss mice (Mus musculus) weighing an average of $39 \mathrm{~g}$ were used. The animals were from the Central Vivarium of the Center of Biological and Health Sciences, Federal University of Mato Grosso do Sul (Centro de Ciências Biológicas e da Saúde da Universidade Federal de Mato Grosso do Sul - CCBS/UFMS). The animals were kept in propylene boxes containing wood shavings, fed a commercial diet (Nuvital Alimentos 
e Produtos Veterinários Ltda. ${ }^{\circledR}$, Curitiba, PR, Brazil), and given filtered water ad libitum. The animals were maintained under standard acclimation conditions in ventilated racks (ALESCO Indústria e Comércio Ltda. ${ }^{\circledR}$, Monte Mor, SP, Brazil) under a 12-h photoperiod (12-h light/12-h dark), at a temperature of approximately $22^{\circ} \pm 2^{\circ} \mathrm{C}$ and a relative humidity of $55 \pm 10 \%$. The experiment complied with the guidelines of the Universal Declaration of Animal Rights and was approved by the animal Ethics Committee of UFMS (ruling \#399/2011).

\section{Experimental design}

The animals were divided into 14 groups and treated as described in Table 1.

\begin{tabular}{|c|c|c|c|c|c|c|}
\hline \multirow[t]{2}{*}{ Experimental groups } & \multicolumn{3}{|c|}{ Initial treatment } & \multicolumn{3}{|c|}{ Treatment after $24 \mathrm{~h}$} \\
\hline & Compound & & Dose & Compound & & Dose \\
\hline \multirow[t]{2}{*}{ C- } & $4 \%$ Tween $+1 \%$ ethanol & po & $0.1 \mathrm{~mL} / 10 \mathrm{~g} \mathrm{bw}$ & $4 \%$ Tween $+1 \%$ ethanol & po & $0.1 \mathrm{~mL} / 10 \mathrm{~g} \mathrm{bw}$ \\
\hline & (physiological saline) & $i p$ & $0.1 \mathrm{~mL} / 10 \mathrm{~g} \mathrm{bw}$ & (physiological saline) & $i p$ & $0.1 \mathrm{~mL} / 10 \mathrm{~g} \mathrm{bw}$ \\
\hline \multirow[t]{2}{*}{$\mathrm{C}+$} & $4 \%$ Tween $+1 \%$ ethanol & po & $0.1 \mathrm{~mL} / 10 \mathrm{~g} \mathrm{bw}$ & $4 \%$ Tween $+1 \%$ ethanol & po & $0.1 \mathrm{~mL} / 10 \mathrm{~g} \mathrm{bw}$ \\
\hline & (cyclophosphamide) & $i p$ & $100 \mathrm{mg} / \mathrm{kg} \mathrm{bw}$ & (physiological saline) & $i p$ & $0.1 \mathrm{~mL} / 10 \mathrm{~g} \mathrm{bw}$ \\
\hline \multirow[t]{2}{*}{$\mathrm{AO} / \mathrm{PO} 3$} & Pulp/Almond oil & po & $3 \mathrm{mg} / \mathrm{kg} \mathrm{bw}$ & $4 \%$ Tween $+1 \%$ ethanol & po & $0.1 \mathrm{~mL} / 10 \mathrm{~g} \mathrm{bw}$ \\
\hline & (physiological saline) & $i p$ & $0.1 \mathrm{~mL} / 10 \mathrm{~g} \mathrm{bw}$ & (physiological saline) & $i p$ & $0.1 \mathrm{~mL} / 10 \mathrm{~g} \mathrm{bw}$ \\
\hline \multirow[t]{2}{*}{$\mathrm{AO} / \mathrm{PO} 15$} & Pulp/Almond oil & po & $15 \mathrm{mg} / \mathrm{kg} \mathrm{bw}$ & $4 \%$ Tween $+1 \%$ ethanol & po & $0.1 \mathrm{~mL} / 10 \mathrm{~g} \mathrm{bw}$ \\
\hline & (physiological saline) & $i p$ & $0.1 \mathrm{~mL} / 10 \mathrm{~g} \mathrm{bw}$ & (physiological saline) & $i p$ & $0.1 \mathrm{~mL} / 10 \mathrm{~g} \mathrm{bw}$ \\
\hline \multirow[t]{2}{*}{$\mathrm{AO} / \mathrm{PO} 30$} & Pulp/Almond oil & po & $30 \mathrm{mg} / \mathrm{kg}$ bw & $4 \%$ Tween $+1 \%$ ethanol & po & $0.1 \mathrm{~mL} / 10 \mathrm{~g} \mathrm{bw}$ \\
\hline & (physiological saline) & $i p$ & $0.1 \mathrm{~mL} / 10 \mathrm{~g} \mathrm{bw}$ & (physiological saline) & $i p$ & $0.1 \mathrm{~mL} / 10 \mathrm{~g} \mathrm{bw}$ \\
\hline \multirow[t]{2}{*}{ Pre 3} & Pulp/Almond oil & po & $3 \mathrm{mg} / \mathrm{kg} \mathrm{bw}$ & $4 \%$ Tween $+1 \%$ ethanol & po & $0.1 \mathrm{~mL} / 10 \mathrm{~g} \mathrm{bw}$ \\
\hline & (physiological saline) & $i p$ & $0.1 \mathrm{~mL} / 10 \mathrm{~g} \mathrm{bw}$ & (cyclophosphamide) & $i p$ & $100 \mathrm{mg} / \mathrm{kg} \mathrm{bw}$ \\
\hline \multirow[t]{2}{*}{ Pre 15} & Pulp/Almond oil & po & $15 \mathrm{mg} / \mathrm{kg}$ bw & $4 \%$ Tween $+1 \%$ ethanol & po & $0.1 \mathrm{~mL} / 10 \mathrm{~g} \mathrm{bw}$ \\
\hline & (physiological saline) & $i p$ & $0.1 \mathrm{~mL} / 10 \mathrm{~g} \mathrm{bw}$ & (cyclophosphamide) & $i p$ & $100 \mathrm{mg} / \mathrm{kg}$ bw \\
\hline \multirow[t]{2}{*}{ Pre 30} & Pulp/Almond oil & po & $30 \mathrm{mg} / \mathrm{kg}$ bw & $4 \%$ Tween $+1 \%$ ethanol & po & $0.1 \mathrm{~mL} / 10 \mathrm{~g} \mathrm{bw}$ \\
\hline & (physiological saline) & $i p$ & $0.1 \mathrm{~mL} / 10 \mathrm{~g} \mathrm{bw}$ & (cyclophosphamide) & $i p$ & $100 \mathrm{mg} / \mathrm{kg}$ bw \\
\hline \multirow[t]{2}{*}{$\operatorname{Sim} 3$} & Pulp/Almond oil & po & $3 \mathrm{mg} / \mathrm{kg}$ bw & $4 \%$ Tween $+1 \%$ ethanol & po & $0.1 \mathrm{~mL} / 10 \mathrm{~g} \mathrm{bw}$ \\
\hline & (cyclophosphamide) & $i p$ & $100 \mathrm{mg} / \mathrm{kg} \mathrm{bw}$ & (physiological saline) & $i p$ & $0.1 \mathrm{~mL} / 10 \mathrm{~g} \mathrm{bw}$ \\
\hline \multirow[t]{2}{*}{ Sim 15} & Pulp/Almond oil & po & $15 \mathrm{mg} / \mathrm{kg}$ bw & $4 \%$ Tween $+1 \%$ ethanol & po & $0.1 \mathrm{~mL} / 10 \mathrm{~g} \mathrm{bw}$ \\
\hline & (cyclophosphamide) & $i p$ & $100 \mathrm{mg} / \mathrm{kg}$ bw & (physiological saline) & $i p$ & $0.1 \mathrm{~mL} / 10 \mathrm{~g} \mathrm{bw}$ \\
\hline \multirow[t]{2}{*}{ Sim 30} & Pulp/Almond oil & po & $30 \mathrm{mg} / \mathrm{kg}$ bw & $4 \%$ Tween $+1 \%$ ethanol & po & $0.1 \mathrm{~mL} / 10 \mathrm{~g} \mathrm{bw}$ \\
\hline & (cyclophosphamide) & $i p$ & $100 \mathrm{mg} / \mathrm{kg}$ bw & (physiological saline) & $i p$ & $0.1 \mathrm{~mL} / 10 \mathrm{~g} \mathrm{bw}$ \\
\hline \multirow[t]{2}{*}{ Post 3} & $4 \%$ Tween $+1 \%$ ethanol & po & $0.1 \mathrm{~mL} / 10 \mathrm{~g} \mathrm{bw}$ & Pulp/Almond oil & po & $15 \mathrm{mg} / \mathrm{kg}$ bw \\
\hline & (cyclophosphamide) & $i p$ & $100 \mathrm{mg} / \mathrm{kg}$ bw & (physiological saline) & $i p$ & $0.1 \mathrm{~mL} / 10 \mathrm{~g} \mathrm{bw}$ \\
\hline \multirow[t]{2}{*}{ Post 15} & $4 \%$ Tween $+1 \%$ ethanol & po & $0.1 \mathrm{~mL} / 10 \mathrm{~g} \mathrm{bw}$ & Pulp/Almond oil & po & $15 \mathrm{mg} / \mathrm{kg}$ bw \\
\hline & (cyclophosphamide) & $i p$ & $100 \mathrm{mg} / \mathrm{kg}$ bw & (physiological saline) & $i p$ & $0.1 \mathrm{~mL} / 10 \mathrm{~g} \mathrm{bw}$ \\
\hline \multirow[t]{2}{*}{ Post 30} & $4 \%$ Tween $+1 \%$ ethanol & po & $0.1 \mathrm{~mL} / 10 \mathrm{~g} \mathrm{bw}$ & Pulp/Almond oil & po & $15 \mathrm{mg} / \mathrm{kg}$ bw \\
\hline & (cyclophosphamide) & $i p$ & $100 \mathrm{mg} / \mathrm{kg} \mathrm{bw}$ & (physiological saline) & $i p$ & $0.1 \mathrm{~mL} / 10 \mathrm{~g} \mathrm{bw}$ \\
\hline
\end{tabular}

C-: negative control group; C+: positive control group; AO: almond oil; PO: pulp oil; Pre: pretreatment; Sim: simultaneous treatment; Post: post-treatment; $p o$ : oral gavage; ip: via intraperitoneal; bw: body weight.

Twenty-four hours after the final administration of treatments (T1), two $20 \mu \mathrm{L}$ peripheral blood samples were collected for the comet and micronucleus assays. Additional peripheral blood samples $(20 \mu \mathrm{L})$ were collected 48 (T2) and $72(\mathrm{~T} 3) \mathrm{h}$ after the final treatment for the micronucleus assay. The animals were then euthanized via cervical dislocation and the spleen, liver, and kidneys were harvested for the spleen phagocytosis and apoptosis tests.

\section{Toxicogenetic assessment}

Approximately one-third of the spleen was macerated with normal saline until a suspension formed. A $100-\mu \mathrm{L}$ aliquot of the suspension was then transferred to a slide that had previously been stained with $20 \mu \mathrm{L}$ acridine orange $(1.0 \mathrm{mg} / \mathrm{mL})$ and covered with a 
cover slip. The slides were stored at $-20^{\circ} \mathrm{C}$ until analysis. Microscopic analysis was performed using a fluorescence microscope (Bioval Representações e Consultoria Ltda. ${ }^{\circledR}$, São Paulo, SP, Brazil, Model L 2000A) under 400X magnification with a 420-490-nm filter and a 520$\mathrm{nm}$ barrier filter. A total of 200 cells were analyzed per animal. The results were categorized according to the presence or absence of phagocytic activity (David et al., 2014).

\section{Differential blood count}

Peripheral blood samples $(20 \mu \mathrm{L})$ were smeared on glass slides. The slides were then dried at room temperature $\left(25^{\circ} \pm 2^{\circ} \mathrm{C}\right)$ and stained with the PanOptic kit (NEWProv Produtos para Laboratório ${ }^{\circledR}$, Pinhais, PR, Brazil, Batch 14429E) according to the manufacturer protocol. The slides were examined using light-field microscopy at a 1000X magnification. A total of 100 cells were analyzed per animal and categorized as lymphocytes, neutrophils, monocytes, eosinophils, and basophils (Navarro et al., 2014).

\section{Apoptosis assay}

Samples $(100 \mu \mathrm{L})$ of macerated spleen, liver and kidney were spread on glass slides. After drying at room temperature, the slides were fixed with Carnoy's solution for $5 \mathrm{~min}$. Next, the slides were subjected to a series of decreasing ethanol concentrations $(95,75,50$, and 25\%), followed by rinsing with McIlvaine buffer for $5 \mathrm{~min}$. The slides were then stained with acridine orange $(0.01 \%)$ for $5 \mathrm{~min}$ and were rinsed again with buffer. A total of 100 cells per animal were analyzed. Apoptotic cells were identified by analyzing the resultant DNA fragmentation patterns (Navarro et al., 2014).

\section{Calculating the percentage of damage reduction} equation:

The percentage of damage reduction (\%DR) was calculated using the following

$\% \mathrm{DR}=\left[\frac{\text { Mean of positive control }- \text { Mean of associated group }}{\text { Mean of positive control - Mean of negative control }}\right] \times 100 \quad$ (Equation 1)

\section{Statistical analysis}

Results are reported as means \pm standard error of the mean (SE). Data were analyzed using two-tailed, unpaired $t$-tests using GraphPad Prism software (Version 3.02; Graph-Pad Software Inc., San Diego, CA, USA). The significance level was set at $\mathrm{P}<0.05$.

\section{RESULTS}

\section{Biometric parameters}

The animals' initial and final body weights were not significantly different $(\mathrm{P}>0.05)$, suggesting that the applied treatments were not toxic (Table 2). 
Table 2. Means $\pm \mathrm{SE}$ of initial and final weight during the experimental period.

\begin{tabular}{l|c|c|c|c}
\hline \multirow{2}{*}{ Experimental groups } & \multicolumn{2}{|c|}{ Animals treated with AO } & \multicolumn{2}{c}{ Animals treated with PO } \\
\cline { 2 - 5 } & Initial weight (g) & Final weight $(\mathrm{g})$ & Initial weight $(\mathrm{g})$ & Final weight $(\mathrm{g})$ \\
\hline C- & $39.20 \pm 3.71$ & $40.00 \pm 3.58$ & $39.20 \pm 3.71$ & $40.00 \pm 3.58$ \\
\hline C+ & $38.80 \pm 1.47^{\mathrm{a}}$ & $40.20 \pm 1.33^{\mathrm{a}}$ & $38.80 \pm 1.47^{\mathrm{a}}$ & $40.20 \pm 1.33^{\mathrm{a}}$ \\
\hline Oil 3 & $40.80 \pm 1.72^{\mathrm{a}}$ & $41.00 \pm 1.10^{\mathrm{a}}$ & $38.80 \pm 1.17^{\mathrm{a}}$ & $38.40 \pm 1.36^{\mathrm{a}}$ \\
\hline Oil 15 & $40.40 \pm 1.50^{\mathrm{a}}$ & $39.60 \pm 1.02^{\mathrm{a}}$ & $39.80 \pm 1.17^{\mathrm{a}}$ & $40.20 \pm 1.60^{\mathrm{a}}$ \\
\hline Oil 30 & $39.60 \pm 1.62^{\mathrm{a}}$ & $39.40 \pm 1.36^{\mathrm{a}}$ & $38.80 \pm 1.72^{\mathrm{a}}$ & $39.80 \pm 1.47^{\mathrm{a}}$ \\
\hline Pre 3 & $39.40 \pm 2.06^{\mathrm{b}}$ & $39.40 \pm 2.24^{\mathrm{b}}$ & $42.20 \pm 1.47^{\mathrm{b}}$ & $39.80 \pm 1.72^{\mathrm{b}}$ \\
\hline Pre 15 & $39.60 \pm 3.32^{\mathrm{b}}$ & $38.40 \pm 3.14^{\mathrm{b}}$ & $39.40 \pm 1.50^{\mathrm{b}}$ & $39.60 \pm 1.50^{\mathrm{b}}$ \\
\hline Pre 30 & $39.80 \pm 0.40^{\mathrm{b}}$ & $39.60 \pm 1.36^{\mathrm{b}}$ & $39.20 \pm 0.75^{\mathrm{b}}$ & $39.40 \pm 1.50^{\mathrm{b}}$ \\
\hline Sim 3 & $39.80 \pm 1.17^{\mathrm{b}}$ & $39.20 \pm 1.33^{\mathrm{b}}$ & $41.20 \pm 1.17^{\mathrm{b}}$ & $40.60 \pm 1.74^{\mathrm{b}}$ \\
\hline Sim 15 & $39.60 \pm 1.02^{\mathrm{b}}$ & $39.20 \pm 1.60^{\mathrm{b}}$ & $40.00 \pm 1.10^{\mathrm{b}}$ & $40.40 \pm 0.80^{\mathrm{b}}$ \\
\hline Sim 30 & $40.20 \pm 1.17^{\mathrm{b}}$ & $40.40 \pm 1.02^{\mathrm{b}}$ & $41.80 \pm 1.33^{\mathrm{b}}$ & $40.40 \pm 2.24^{\mathrm{b}}$ \\
\hline Post 3 & $39.00 \pm 0.89^{\mathrm{b}}$ & $38.80 \pm 0.75^{\mathrm{b}}$ & $39.40 \pm 1.50^{\mathrm{b}}$ & $37.80 \pm 2.14^{\mathrm{b}}$ \\
\hline Post 15 & $39.80 \pm 1.47^{\mathrm{b}}$ & $39.60 \pm 2.65^{\mathrm{b}}$ & $41.20 \pm 1.47^{\mathrm{b}}$ & $40.40 \pm 0.49^{\mathrm{b}}$ \\
\hline Post 30 & $40.80 \pm 0.98^{\mathrm{b}}$ & $39.60 \pm 1.85^{\mathrm{b}}$ & $41.80 \pm 1.33^{\mathrm{b}}$ & $40.80 \pm 0.75^{\mathrm{b}}$ \\
\hline
\end{tabular}

SE: standard error; C-: negative control group; $\mathrm{C}+$ : positive control group; AO: almond oil; PO: pulp oil; Pre: pretreatment; Sim: simultaneous treatment; Post: post-treatment; ${ }^{\mathrm{a}}$ compared with negative control; ${ }^{\mathrm{b}} \mathrm{compared}$ with positive control.

\section{Toxicogenetic action}

Neither AO nor PO caused toxicogenetic damage, as comets and micronuclei were equally frequent in the treatments and in the negative control $(P>0.05$; Tables 3 and 4$)$. The chemopreventive action of the oils was demonstrated by the high \%DR values in both the antigenotoxicity and antimutagenicity tests relative to pretreatment, simultaneous treatment, and post-treatment values at all three doses (Tables 3 and 4).

The \%DR values in the antigenotoxicity analysis of AO were 70.60-80.05, 64.5769.29 , and $78.74-88.19 \%$ for the pretreatment, simultaneous treatment, and post-treatment protocols, respectively. The corresponding \%DR of PO were 82.68-87.66, 64.57-78.22, and $85.04-90.03 \%$ for the pretreatment, simultaneous treatment, and post-treatment protocols, respectively (Table 3 ).

In the antimutagenicity analysis of $\mathrm{AO}$, the $\% \mathrm{DR}$ values corresponding to the pretreatment, simultaneous treatment, and post-treatment protocols were 59.11-61.66, 40.8968.69 , and 57.19-68.05\%, respectively, at T1. These values were 54.59-60.54, 29.19-63.24, and $47.57-69.73 \%$ at $\mathrm{T} 2$. These values were $37.84-58.56,26.13-56.76$, and $50.45-64.86 \%$ at T3. For PO, the corresponding \%DR values were $60.70-70.93,12.14-42.49$, and 61.98 $67.09 \%$, respectively, at T1. These values were $60.54-66.49,26.49-56.76$, and $49.73-56.76 \%$ at T2. These values were $36.94-55.86,40.54-59.46$, and $21.62-44.14 \%$ at T3. Statistical analysis demonstrated the efficiency of the chemopreventive treatment under all doses and protocols with the exception of I) the lowest dose of AO in the pretreatment protocol at T3; II) the lowest PO dose in the simultaneous treatment protocol at T1; and III) the lowest PO dose in the post-treatment protocol at T3 (Table 4).

\section{Immunomodulation}

Administration of both oils increased immunomodulatory activity by $1.15-$ and 1.17 fold $(\mathrm{P}<0.05)$. The oils reduced the rate of cyclophosphamide-induced spleen phagocytic activity under all doses and protocols by approximately 1.73 -fold $(\mathrm{P}<0.05)$. This effect was most remarkable for the pretreatment protocol at the highest dose and for the simultaneous 
Table 3. Means \pm SE frequency of damaged cells, distribution between damage classes, and antigenotoxicity/ genotoxicity scores via the comet assay in mouse peripheral blood cells.

\begin{tabular}{|c|c|c|c|c|c|c|c|}
\hline \multirow{2}{*}{ Experimental groups } & \multirow{2}{*}{ Damaged cells } & \multicolumn{4}{|c|}{ Damage classes } & \multirow{2}{*}{ Score } & \multirow[t]{2}{*}{$\% \mathrm{RD}$} \\
\hline & & 0 & 1 & 2 & 3 & & \\
\hline \multicolumn{8}{|l|}{ Almond oil } \\
\hline $\mathrm{C}-$ & $10.40 \pm 1.85$ & $89.60 \pm 1.85$ & $10.40 \pm 1.85$ & $0.00 \pm 0.00$ & $0.00 \pm 0.00$ & $10.40 \pm 1.85$ & - \\
\hline $\mathrm{C}+$ & $86.60 \pm 2.58^{\mathrm{a}^{*}}$ & $13.40 \pm 2.58$ & $37.80 \pm 5.23$ & $25.40 \pm 3.26$ & $23.40 \pm 1.62$ & $158.80 \pm 5.67^{\mathrm{a}^{*}}$ & - \\
\hline $\mathrm{AO} 3$ & $7.00 \pm 3.29^{\mathrm{a}}$ & $93.00 \pm 3.29$ & $6.60 \pm 3.01$ & $0.40 \pm 0.80$ & $0.00 \pm 0.00$ & $7.40 \pm 3.72^{\mathrm{a}}$ & - \\
\hline $\mathrm{AO} 15$ & $11.60 \pm 3.38^{\mathrm{a}}$ & $88.40 \pm 3.38$ & $8.20 \pm 2.40$ & $2.60 \pm 1.36$ & $0.80 \pm 0.75$ & $15.80 \pm 5.56^{\mathrm{a}}$ & - \\
\hline $\mathrm{AO} 30$ & $11.40 \pm 7.34^{\mathrm{a}}$ & $88.60 \pm 7.34$ & $6.00 \pm 4.56$ & $4.00 \pm 2.19$ & $1.40 \pm 1.36$ & $18.20 \pm 11.75^{\mathrm{a}}$ & - \\
\hline Pre 3 & $32.40 \pm 3.88^{\mathrm{b}^{*}}$ & $67.60 \pm 3.88$ & $20.60 \pm 5.12$ & $9.00 \pm 2.28$ & $2.80 \pm 1.47$ & $47.00 \pm 4.47^{b^{*}}$ & 71.13 \\
\hline Pre 15 & $32.80 \pm 4.26^{\mathrm{b}^{*}}$ & $67.20 \pm 4.26$ & $17.80 \pm 2.32$ & $11.20 \pm 1.72$ & $3.80 \pm 2.32$ & $51.60 \pm 8.28^{\mathrm{b}^{*}}$ & 70.60 \\
\hline Pre 30 & $25.60 \pm 3.93^{\mathrm{b}^{*}}$ & $74.40 \pm 3.93$ & $14.80 \pm 1.47$ & $6.60 \pm 1.50$ & $4.20 \pm 2.40$ & $40.60 \pm 8.64^{b^{*}}$ & 80.05 \\
\hline Sim 3 & $35.60 \pm 5.68^{\mathrm{b}^{*}}$ & $64.40 \pm 5.68$ & $21.60 \pm 1.85$ & $9.20 \pm 2.71$ & $4.80 \pm 3.66$ & $54.40 \pm 14.15^{\mathrm{b}^{*}}$ & 66.93 \\
\hline Sim 15 & $37.40 \pm 5.35^{\mathrm{b}^{*}}$ & $62.60 \pm 5.35$ & $23.20 \pm 2.79$ & $9.80 \pm 5.64$ & $4.40 \pm 3.26$ & $56.00 \pm 12.33^{\mathrm{b}^{*}}$ & 64.57 \\
\hline Sim 30 & $33.80 \pm 12.64^{\mathrm{b}^{*}}$ & $66.20 \pm 12.64$ & $22.20 \pm 6.76$ & $8.40 \pm 4.32$ & $3.20 \pm 2.32$ & $48.60 \pm 20.77^{b^{*}}$ & 69.29 \\
\hline Post 3 & $26.60 \pm 9.20^{\mathrm{b}^{*}}$ & $73.40 \pm 9.20$ & $17.20 \pm 3.19$ & $5.80 \pm 4.58$ & $3.60 \pm 2.94$ & $39.60 \pm 18.83^{b^{*}}$ & 78.74 \\
\hline Post 15 & $23.00 \pm 3.16^{\mathrm{b}^{*}}$ & $77.00 \pm 3.16$ & $16.40 \pm 2.58$ & $4.20 \pm 2.14$ & $2.40 \pm 1.50$ & $32.00 \pm 4.77^{b^{*}}$ & 83.46 \\
\hline Post 30 & $19.40 \pm 8.82^{\mathrm{b}^{*}}$ & $80.60 \pm 8.82$ & $11.20 \pm 4.71$ & $6.80 \pm 3.37$ & $1.40 \pm 1.50$ & $29.00 \pm 14.30^{b^{*}}$ & 88.19 \\
\hline \multicolumn{8}{|l|}{ Pulp oil } \\
\hline $\mathrm{C}-$ & $10.40 \pm 1.85$ & $89.60 \pm 1.85$ & $10.40 \pm 1.85$ & $0.00 \pm 0.00$ & $0.00 \pm 0.00$ & $10.40 \pm 1.85$ & - \\
\hline $\mathrm{C}+$ & $86.60 \pm 2.58^{\mathrm{a}^{*}}$ & $13.40 \pm 2.58$ & $37.80 \pm 5.23$ & $25.40 \pm 3.26$ & $23.40 \pm 1.62$ & $158.80 \pm 5.67^{\mathrm{a}^{*}}$ & - \\
\hline $\mathrm{PO} 3$ & $10.60 \pm 2.58^{\mathrm{a}}$ & $89.40 \pm 2.58$ & $7.80 \pm 1.72$ & $2.00 \pm 0.63$ & $0.80 \pm 0.75$ & $14.20 \pm 4.45^{\mathrm{a}}$ & - \\
\hline PO 15 & $6.80 \pm 3.31^{\mathrm{a}}$ & $93.20 \pm 3.31$ & $5.00 \pm 2.76$ & $1.60 \pm 0.49$ & $0.20 \pm 0.40$ & $8.80 \pm 4.12^{\mathrm{a}}$ & - \\
\hline PO 30 & $8.60 \pm 2.42^{\mathrm{a}}$ & $91.40 \pm 2.42$ & $6.40 \pm 1.20$ & $1.80 \pm 0.98$ & $0.40 \pm 0.49$ & $11.20 \pm 4.12^{\mathrm{a}}$ & - \\
\hline Pre 3 & $22.40 \pm 4.76^{\mathrm{b}^{*}}$ & $77.60 \pm 4.76$ & $16.00 \pm 2.45$ & $5.20 \pm 1.47$ & $1.20 \pm 1.17$ & $30.00 \pm 8.27^{\mathrm{b}^{*}}$ & 84.25 \\
\hline Pre 15 & $23.60 \pm 2.15^{\mathrm{b}^{*}}$ & $76.40 \pm 2.15$ & $16.60 \pm 1.74$ & $5.60 \pm 0.80$ & $1.40 \pm 0.49$ & $32.00 \pm 3.16^{b^{*}}$ & 82.68 \\
\hline Pre 30 & $19.80 \pm 4.45^{\mathrm{b}^{*}}$ & $80.20 \pm 4.45$ & $13.60 \pm 2.73$ & $4.00 \pm 1.26$ & $2.20 \pm 1.47$ & $28.20 \pm 8.08^{\mathrm{b}^{*}}$ & 87.66 \\
\hline Sim 3 & $37.40 \pm 4.80^{\mathrm{b}^{*}}$ & $62.60 \pm 4.80$ & $20.20 \pm 1.94$ & $12.20 \pm 2.23$ & $5.00 \pm 1.79$ & $59.60 \pm 9.18^{\mathrm{b}^{*}}$ & 64.57 \\
\hline Sim 15 & $27.60 \pm 1.74^{\mathrm{b}^{*}}$ & $72.40 \pm 1.74$ & $15.40 \pm 1.85$ & $7.80 \pm 0.98$ & $4.40 \pm 0.49$ & $44.20 \pm 1.94^{\mathrm{b}^{*}}$ & 77.43 \\
\hline Sim 30 & $27.00 \pm 5.73^{\mathrm{b}^{*}}$ & $73.00 \pm 5.73$ & $18.00 \pm 3.63$ & $5.40 \pm 2.87$ & $3.60 \pm 1.62$ & $39.60 \pm 10.8^{b^{*}}$ & 78.22 \\
\hline Post 3 & $21.80 \pm 5.23^{\mathrm{b}^{*}}$ & $78.20 \pm 5.23$ & $16.00 \pm 2.45$ & $3.20 \pm 1.72$ & $2.60 \pm 1.96$ & $30.20 \pm 10.34^{b^{*}}$ & 85.04 \\
\hline Post 15 & $20.60 \pm 3.72^{\mathrm{b}^{*}}$ & $79.40 \pm 3.72$ & $15.80 \pm 1.33$ & $3.80 \pm 2.79$ & $1.00 \pm 0.63$ & $26.40 \pm 7.06^{\mathrm{b}^{*}}$ & 86.61 \\
\hline Post 30 & $18.00 \pm 6.54^{\mathrm{b}^{*}}$ & $82.00 \pm 6.54$ & $11.40 \pm 6.62$ & $4.20 \pm 1.60$ & $2.40 \pm 1.36$ & $27.00 \pm 8.00^{\mathrm{b}^{*}}$ & 90.03 \\
\hline
\end{tabular}

SE: standard error; DR\%: damage reduction percentage; $\mathrm{C}$-: negative control group; $\mathrm{C}+$ : positive control group; AO: almond oil; PO: pulp oil; Pre: pretreatment; Sim: simultaneous treatment; Post: post-treatment; ${ }^{a}$ compared with negative control; ${ }^{\mathrm{b}}$ compared with positive control; * Statistically significant differences $(\mathrm{P}<0.05)$.

treatment protocol at the lowest dose, where reductions of 43.8 and $44.4 \%$ relative to the positive control were observed for $\mathrm{AO}$ and $\mathrm{PO}$, respectively. The smallest effects ( 8.6 and 7\%) were obtained under the simultaneous treatment protocol at the highest doses of $\mathrm{AO}$ and $\mathrm{PO}$, respectively (Table 5).

The results regarding the differential blood count obtained in the experiments with AO were as follows: I) discrete lymphocytopenia was observed in the animals pretreated with the two highest doses, in animals subjected to simultaneous treatment with the intermediate dose, and in the animals post-treated with the highest dose $(\mathrm{P}<0.05)$; II) discrete neutrophilia occurred in the animals pretreated with the two highest doses and in those subjected to simultaneous treatment with the intermediate dose $(\mathrm{P}<0.05)$; and III) monocyte, eosinophil, and basophil counts were not significantly different from the reference values, except for those in the group pretreated with the intermediate dose. This group exhibited a significant reduction in the basophil count $(\mathrm{P}<0.05)$ compared with that of the positive control (Table 6). The results for the experiments with PO were as follows: I) discrete lymphocytopenia was observed in the PO group pretreated with the intermediate dose, in the mice subjected to simultaneous treatment with the two highest doses, and in the mice post-treated with the highest dose $(\mathrm{P}<$ $0.05)$; II) discrete neutrophilia was found in the animals treated with the intermediate dose, 
those subjected to simultaneous treatment with the two highest doses, and those post-treated with the highest dose ( $\mathrm{P}>0.05)$; and III) monocyte, eosinophil, and basophil counts did not differ from the reference values (Table 6).

Table 4. Total frequency and means \pm SE of the micronucleus assay in mouse peripheral blood cells.

\begin{tabular}{|c|c|c|c|c|c|c|c|c|c|}
\hline \multirow[t]{2}{*}{ Experimental groups } & \multicolumn{3}{|c|}{ Micronucleus frequency } & \multicolumn{3}{|c|}{ Means \pm SE } & \multicolumn{3}{|c|}{$\% \mathrm{DR}$} \\
\hline & $24 \mathrm{~h}(\mathrm{~T} 1)$ & $48 \mathrm{~h}(\mathrm{~T} 2)$ & $72 \mathrm{~h}(\mathrm{~T} 3)$ & $24 \mathrm{~h}(\mathrm{~T} 1)$ & $48 \mathrm{~h}(\mathrm{~T} 2)$ & $72 \mathrm{~h}(\mathrm{~T} 3)$ & $24 \mathrm{~h}$ & $48 \mathrm{~h}$ & $72 \mathrm{~h}$ \\
\hline \multicolumn{10}{|l|}{ Almond oil } \\
\hline $\mathrm{C}-$ & 73 & 61 & 50 & $14.60 \pm 2.15$ & $12.20 \pm 1.94$ & $10.00 \pm 1.41$ & - & - & - \\
\hline $\mathrm{C}+$ & 386 & 246 & 161 & $77.20 \pm 7.83^{\mathrm{a}^{*}}$ & $49.20 \pm 3.49^{\mathrm{a}^{*}}$ & $32.20 \pm 3.54^{\mathrm{a}^{*}}$ & - & - & - \\
\hline $\mathrm{AO} 3$ & 56 & 51 & 49 & $11.20 \pm 1.94^{\mathrm{a}}$ & $10.20 \pm 1.72^{\mathrm{a}}$ & $9.80 \pm 0.75^{\mathrm{a}}$ & - & - & - \\
\hline $\mathrm{AO} 15$ & 57 & 53 & 47 & $11.40 \pm 1.74^{\mathrm{a}}$ & $10.60 \pm 2.06^{\mathrm{a}}$ & $9.40 \pm 1.74^{\mathrm{a}}$ & - & - & - \\
\hline $\mathrm{AO} 30$ & 74 & 61 & 48 & $14.80 \pm 4.26^{\mathrm{a}}$ & $12.20 \pm 2.79^{\mathrm{a}}$ & $9.60 \pm 2.24^{\mathrm{a}}$ & - & - & - \\
\hline Pre 3 & 193 & 134 & 119 & $38.60 \pm 4.03^{\mathrm{b}^{*}}$ & $26.80 \pm 3.31^{\mathrm{b}^{*}}$ & $23.80 \pm 16.41^{\mathrm{b}}$ & 61.66 & 60.54 & 37.84 \\
\hline Pre 15 & 201 & 145 & 98 & $40.20 \pm 2.14^{\mathrm{b}^{*}}$ & $29.00 \pm 2.45^{\mathrm{b} *}$ & $19.60 \pm 1.50^{\mathrm{b} *}$ & 59.11 & 54.59 & 56.76 \\
\hline Pre 30 & 197 & 141 & 96 & $39.40 \pm 1.74^{\mathrm{b}^{*}}$ & $28.20 \pm 1.33^{\mathrm{b}^{*}}$ & $19.20 \pm 2.71^{\mathrm{b} *}$ & 60.38 & 56.76 & 58.56 \\
\hline $\operatorname{Sim} 3$ & 258 & 192 & 132 & $51.60 \pm 3.98^{\mathrm{b}^{*}}$ & $38.40 \pm 6.41^{\mathrm{b}^{*}}$ & $26.40 \pm 1.85^{\mathrm{b} *}$ & 40.89 & 29.19 & 26.13 \\
\hline Sim 15 & 209 & 143 & 98 & $41.80 \pm 2.79^{\mathrm{b}^{*}}$ & $28.60 \pm 3.26^{b^{*}}$ & $19.60 \pm 1.74^{\mathrm{b}^{*}}$ & 56.55 & 55.68 & 56.76 \\
\hline Sim 30 & 171 & 129 & 104 & $34.20 \pm 2.14^{\mathrm{b}^{*}}$ & $25.80 \pm 1.94^{\mathrm{b*}}$ & $20.80 \pm 1.17^{b^{*}}$ & 68.69 & 63.24 & 51.35 \\
\hline Post 3 & 207 & 158 & 105 & $41.40 \pm 4.59^{\mathrm{b}^{*}}$ & $31.60 \pm 1.85^{\mathrm{b}^{*}}$ & $21.00 \pm 1.41^{\mathrm{b}^{*}}$ & 57.19 & 47.57 & 50.45 \\
\hline Post 15 & 173 & 117 & 102 & $34.60 \pm 3.44^{\mathrm{b}^{*}}$ & $23.40 \pm 3.90^{\mathrm{b*}}$ & $20.40 \pm 3.61^{\mathrm{b}^{*}}$ & 68.05 & 69.73 & 53.15 \\
\hline Post 30 & 176 & 128 & 89 & $35.20 \pm 2.32^{\mathrm{b}^{*}}$ & $25.60 \pm 2.58^{\mathrm{b}^{*}}$ & $17.80 \pm 1.83^{b^{*}}$ & 67.09 & 63.78 & 64.86 \\
\hline \multicolumn{10}{|l|}{ Pulp oil } \\
\hline $\mathrm{C}$ - & 73 & 61 & 50 & $14.60 \pm 2.15$ & $12.20 \pm 1.94$ & $10.00 \pm 1.41$ & - & - & - \\
\hline $\mathrm{C}+$ & 386 & 246 & 161 & $77.20 \pm 7.83^{\mathrm{a}^{*}}$ & $49.20 \pm 3.49^{\mathrm{a}^{*}}$ & $32.20 \pm 3.54^{\mathrm{a}^{*}}$ & - & - & - \\
\hline $\mathrm{PO} 3$ & 78 & 45 & 38 & $15.60 \pm 6.41^{\mathrm{a}}$ & $9.00 \pm 2.00^{\mathrm{a}}$ & $7.60 \pm 3.07^{\mathrm{a}}$ & - & - & - \\
\hline PO 15 & 65 & 42 & 35 & $13.00 \pm 3.90^{\mathrm{a}}$ & $8.40 \pm 2.58^{\mathrm{a}}$ & $7.00 \pm 3.29^{\mathrm{a}}$ & - & - & - \\
\hline PO 30 & 54 & 53 & 50 & $10.80 \pm 6.49^{\mathrm{a}}$ & $10.60 \pm 1.74^{\mathrm{a}}$ & $10.00 \pm 1.41^{\mathrm{a}}$ & - & - & - \\
\hline Pre 3 & 196 & 134 & 101 & $39.20 \pm 9.91^{\mathrm{b}^{*}}$ & $26.80 \pm 3.87^{b^{*}}$ & $20.20 \pm 1.72^{\mathrm{b}^{*}}$ & 60.70 & 60.54 & 54.05 \\
\hline Pre 15 & 164 & 133 & 120 & $32.80 \pm 5.95^{\mathrm{b}^{*}}$ & $26.60 \pm 2.87^{b^{*}}$ & $24.00 \pm 4.34^{\mathrm{b} *}$ & 70.93 & 61.08 & 36.94 \\
\hline Pre 30 & 175 & 123 & 99 & $35.00 \pm 12.65^{\mathrm{b}^{*}}$ & $24.60 \pm 1.62^{\mathrm{b}^{*}}$ & $19.80 \pm 1.33^{\mathrm{b}^{*}}$ & 67.41 & 66.49 & 55.86 \\
\hline $\operatorname{Sim} 3$ & 348 & 197 & 116 & $69.60 \pm 9.91^{\mathrm{b}}$ & $39.40 \pm 3.61^{\mathrm{b}^{*}}$ & $23.20 \pm 3.31^{\mathrm{b}^{*}}$ & 12.14 & 26.49 & 40.54 \\
\hline Sim 15 & 296 & 165 & 111 & $59.20 \pm 7.91^{\mathrm{b}^{*}}$ & $33.00 \pm 4.60^{\mathrm{b}^{*}}$ & $22.20 \pm 3.37^{\mathrm{b}^{*}}$ & 28.75 & 43.78 & 45.05 \\
\hline Sim 30 & 253 & 141 & 95 & $50.60 \pm 6.92^{\mathrm{b}^{*}}$ & $28.20 \pm 2.56^{\mathrm{b}^{*}}$ & $19.00 \pm 2.28^{\mathrm{b} *}$ & 42.49 & 56.76 & 59.46 \\
\hline Post 3 & 183 & 147 & 137 & $36.60 \pm 3.20^{\mathrm{b}^{*}}$ & $29.40 \pm 2.06^{\mathrm{b}^{*}}$ & $27.40 \pm 2.33^{\mathrm{b}}$ & 64.86 & 53.51 & 21.62 \\
\hline Post 15 & 192 & 154 & 124 & $38.40 \pm 5.68^{\mathrm{b}^{*}}$ & $30.80 \pm 4.79^{\mathrm{b} *}$ & $24.80 \pm 3.76^{\mathrm{b}^{*}}$ & 61.98 & 49.73 & 33.33 \\
\hline Post 30 & 176 & 141 & 112 & $35.20 \pm 4.17^{b^{*}}$ & $28.20 \pm 3.82^{\mathrm{b}^{*}}$ & $22.40 \pm 1.96^{\mathrm{b}^{*}}$ & 67.09 & 56.76 & 44.14 \\
\hline
\end{tabular}

SE: standard error; DR\%: damage reduction percentage; $\mathrm{C}$-: negative control group; $\mathrm{C}+$ : positive control group; AO: almond oil; PO: pulp oil; Pre: pretreatment; Sim: simultaneous treatment; Post: post-treatment. ${ }^{a}$ Compared with negative control; ${ }^{b}$ compared with positive control; * statistically significant differences $(\mathrm{P}<0.05)$.

Table 5. Number of analyzed cells, mean frequency \pm SE, and cell percentage with or without evidence of splenic phagocytosis.

\begin{tabular}{l|c|c|c|c|c|c|c}
\hline \multirow{2}{*}{} & Number of analyzed cells & \multicolumn{5}{|c}{ Total of cells with evidence of phagocytosis } \\
\cline { 3 - 8 } & & \multicolumn{7}{|c|}{ Almond oil } & \multicolumn{3}{c}{ Pulp oil } \\
\cline { 3 - 8 } & & Absolute values & Mean \pm SE & Percentage (\%) & Absolute values & Mean \pm SE & Percentage (\%) \\
\hline C- & 1000 & 439 & $87.80 \pm 4.31$ & 43.90 & 439 & $87.80 \pm 4.31$ & 43.90 \\
\hline C+ & 1000 & 760 & $152.00 \pm 4.69^{a^{*}}$ & 76.00 & 760 & $152.00 \pm 4.69^{a^{*}}$ & 76.00 \\
\hline Oil 3 & 1000 & 505 & $101.00 \pm 3.03^{a^{*}}$ & 50.50 & 506 & $101.20 \pm 1.17^{a^{*}}$ & 50.60 \\
\hline Oil 15 & 1000 & 475 & $95.00 \pm 4.77^{\mathrm{a}}$ & 47.50 & 474 & $94.80 \pm 8.13^{\mathrm{a}}$ & 47.40 \\
\hline Oil 30 & 1000 & 513 & $102.60 \pm 5.85^{\mathrm{a}^{*}}$ & 51.30 & 507 & $101.40 \pm 2.58^{\mathrm{a}^{*}}$ & 50.70 \\
\hline Pre 3 & 1000 & 582 & $116.40 \pm 5.31^{\mathrm{b}^{*}}$ & 58.20 & 566 & $113.20 \pm 4.84^{\mathrm{b}^{*}}$ & 56.60 \\
\hline Pre 15 & 1000 & 553 & $110.60 \pm 4.80^{\mathrm{b}^{*}}$ & 55.30 & 545 & $109.00 \pm 7.24^{\mathrm{b}^{*}}$ & 54.50 \\
\hline Pre 30 & 1000 & 541 & $108.20 \pm 5.31^{\mathrm{b}^{*}}$ & 54.10 & 538 & $107.60 \pm 4.84^{\mathrm{b}^{*}}$ & 53.80 \\
\hline Sim 3 & 1000 & 542 & $108.40 \pm 7.00^{\mathrm{b}^{*}}$ & 54.20 & 501 & $100.20 \pm 2.99^{\mathrm{b}^{*}}$ & 50.10 \\
\hline Sim 15 & 1000 & 657 & $131.40 \pm 4.27^{\mathrm{b}^{*}}$ & 65.70 & 667 & $133.40 \pm 7.50^{\mathrm{b}^{*}}$ & 66.70 \\
\hline Sim 30 & 1000 & 717 & $143.40 \pm 9.39^{\mathrm{b}}$ & 71.70 & 725 & $145.00 \pm 7.29^{\mathrm{b}}$ & 72.50 \\
\hline Post 3 & 1000 & 591 & $118.20 \pm 5.91^{\mathrm{b}^{*}}$ & 59.10 & 600 & $120.00 \pm 5.10^{\mathrm{b}^{*}}$ & 60.00 \\
\hline Post 15 & 1000 & 631 & $126.20 \pm 6.08^{\mathrm{b}^{*}}$ & 63.10 & 638 & $127.60 \pm 8.96^{\mathrm{b}^{*}}$ & 63.80 \\
\hline Post 30 & 1000 & 638 & $127.60 \pm 8.45^{\mathrm{b}^{*}}$ & 63.80 & 631 & $126.20 \pm 8.13^{\mathrm{b}^{*}}$ & 63.10 \\
\hline
\end{tabular}

SE: standard error; C-: negative control group; $\mathrm{C}+$ : positive control group; Pre: pretreatment; Sim: simultaneous treatment; Post: post-treatment. ${ }^{a}$ Compared with negative control; ${ }^{b}$ compared with positive control; *statistically significant differences $(\mathrm{P}<0.05)$. 
Table 6. Reference values (in parentheses) and means $\pm \mathrm{SE}$ of differential blood cell counts.

\begin{tabular}{|c|c|c|c|c|c|}
\hline & Lymphocyte & Neutrophil & Monocyte & Eosinophil & Basophil \\
\hline & $(55-95 \%)$ & $(10-40 \%)$ & $(0.1-3.5 \%)$ & $(0-0.4 \%)$ & $(0-0.3 \%)$ \\
\hline \multicolumn{6}{|c|}{ Almond oil } \\
\hline C- & $57.00 \pm 2.76$ & $37.60 \pm 2.42$ & $3.20 \pm 0.75$ & $1.60 \pm 0.80$ & $0.60 \pm 0.80$ \\
\hline $\mathrm{C}+$ & $57.20 \pm 1.33^{\mathrm{a}}$ & $37.00 \pm 0.63^{\mathrm{a}}$ & $3.00 \pm 0.89^{\mathrm{a}}$ & $1.60 \pm 0.49^{\mathrm{a}}$ & $1.20 \pm 0.40^{\mathrm{a}}$ \\
\hline $\mathrm{AO} 3$ & $56.20 \pm 2.14^{\mathrm{a}}$ & $39.40 \pm 1.50^{\mathrm{a}}$ & $2.80 \pm 0.75^{\mathrm{a}}$ & $1.00 \pm 0.63^{\mathrm{a}}$ & $0.60 \pm 0.80^{\mathrm{a}}$ \\
\hline AO 15 & $56.00 \pm 1.90^{\mathrm{a}}$ & $39.80 \pm 3.19^{\mathrm{a}}$ & $2.60 \pm 0.80^{\mathrm{a}}$ & $1.00 \pm 0.63^{\mathrm{a}}$ & $0.60 \pm 0.80^{\mathrm{a}}$ \\
\hline $\mathrm{AO} 30$ & $57.20 \pm 1.33^{\mathrm{a}}$ & $37.60 \pm 1.50^{\mathrm{a}}$ & $3.20 \pm 0.75^{\mathrm{a}}$ & $1.40 \pm 0.80^{\mathrm{a}}$ & $0.60 \pm 0.49^{\mathrm{a}}$ \\
\hline Pre 3 & $56.40 \pm 1.02^{\mathrm{b}}$ & $38.00 \pm 1.41^{\mathrm{b}}$ & $3.00 \pm 0.63^{b}$ & $2.20 \pm 0.98^{\mathrm{b}}$ & $0.40 \pm 0.49^{\mathrm{b}}$ \\
\hline Pre 15 & $53.60 \pm 1.85^{\mathrm{b}^{*}}$ & $42.40 \pm 2.73^{b^{*}}$ & $2.80 \pm 0.75^{\mathrm{b}}$ & $1.00 \pm 0.89^{\mathrm{b}}$ & $0.20 \pm 0.40^{\mathrm{b}^{*}}$ \\
\hline Pre 30 & $51.80 \pm 1.60^{\mathrm{b}^{*}}$ & $43.00 \pm 2.61^{\mathrm{b}^{*}}$ & $3.00 \pm 0.89^{\mathrm{b}}$ & $1.60 \pm 1.02^{\mathrm{b}}$ & $0.60 \pm 0.80^{\mathrm{b}}$ \\
\hline Sim 3 & $55.80 \pm 3.29^{\mathrm{b}}$ & $39.00 \pm 3.29^{\mathrm{b}}$ & $2.80 \pm 1.17^{\mathrm{b}}$ & $2.00 \pm 0.63^{b}$ & $0.40 \pm 0.80^{\mathrm{b}}$ \\
\hline Sim 15 & $53.60 \pm 1.02^{\mathrm{b}^{*}}$ & $42.60 \pm 2.42^{b^{*}}$ & $2.20 \pm 0.98^{\mathrm{b}}$ & $1.20 \pm 0.75^{\mathrm{b}}$ & $0.40 \pm 0.49^{b}$ \\
\hline Sim 30 & $56.20 \pm 2.48^{b}$ & $38.60 \pm 2.73^{\mathrm{b}}$ & $2.80 \pm 0.75^{\mathrm{b}}$ & $1.80 \pm 0.40^{\mathrm{b}}$ & $0.60 \pm 0.49^{b}$ \\
\hline Post 3 & $56.60 \pm 1.85^{\mathrm{b}}$ & $38.00 \pm 2.10^{\mathrm{b}}$ & $3.40 \pm 0.80^{\mathrm{b}}$ & $1.20 \pm 0.75^{\mathrm{b}}$ & $0.80 \pm 0.75^{\mathrm{b}}$ \\
\hline Post 15 & $57.80 \pm 2.14^{\mathrm{b}}$ & $37.20 \pm 2.04^{\mathrm{b}}$ & $2.60 \pm 0.80^{\mathrm{b}}$ & $1.80 \pm 0.40^{\mathrm{b}}$ & $0.60 \pm 0.49^{b}$ \\
\hline Post 30 & $54.60 \pm 1.36^{\mathrm{b}^{*}}$ & $39.40 \pm 1.85^{\mathrm{b}}$ & $3.60 \pm 0.49^{\mathrm{b}}$ & $1.60 \pm 0.80^{\mathrm{b}}$ & $0.80 \pm 0.75^{\mathrm{b}}$ \\
\hline \multicolumn{6}{|l|}{ Pulp oil } \\
\hline C- & $57.00 \pm 2.76$ & $37.60 \pm 2.42$ & $3.20 \pm 0.75$ & $1.60 \pm 0.80$ & $0.60 \pm 0.80$ \\
\hline $\mathrm{C}+$ & $57.20 \pm 1.33^{\mathrm{a}}$ & $37.00 \pm 0.63^{\mathrm{a}}$ & $3.00 \pm 0.89^{\mathrm{a}}$ & $1.60 \pm 0.49^{\mathrm{a}}$ & $1.20 \pm 0.40^{\mathrm{a}}$ \\
\hline PO 3 & $56.00 \pm 3.41^{\mathrm{a}}$ & $40.60 \pm 4.22^{\mathrm{a}}$ & $2.00 \pm 0.63^{\mathrm{a}}$ & $1.00 \pm 0.89^{\mathrm{a}}$ & $0.40 \pm 0.49^{\mathrm{a}}$ \\
\hline PO 15 & $52.80 \pm 2.14^{\mathrm{a}^{*}}$ & $43.20 \pm 3.31^{\mathrm{a}^{*}}$ & $2.40 \pm 0.49^{\mathrm{a}}$ & $1.20 \pm 0.98^{\mathrm{a}}$ & $0.40 \pm 0.49^{\mathrm{a}}$ \\
\hline PO 30 & $56.80 \pm 1.17^{\mathrm{a}}$ & $37.60 \pm 1.02^{\mathrm{a}}$ & $3.00 \pm 0.63^{\mathrm{a}}$ & $2.20 \pm 0.98^{\mathrm{a}}$ & $0.40 \pm 0.49^{\mathrm{a}}$ \\
\hline Pre 3 & $55.40 \pm 1.50^{\mathrm{b}}$ & $40.20 \pm 2.93^{\mathrm{b}}$ & $3.00 \pm 0.89^{\mathrm{b}}$ & $0.80 \pm 0.75^{\mathrm{b}}$ & $0.60 \pm 0.80^{\mathrm{b}}$ \\
\hline Pre 15 & $54.20 \pm 1.94^{\mathrm{b}^{*}}$ & $39.20 \pm 1.17^{\mathrm{b}}$ & $3.40 \pm 1.20^{\mathrm{b}}$ & $2.40 \pm 1.02^{\mathrm{b}}$ & $0.80 \pm 0.75^{\mathrm{b}}$ \\
\hline Pre 30 & $55.40 \pm 1.62^{\mathrm{b}}$ & $39.00 \pm 1.79^{\mathrm{b}}$ & $3.00 \pm 0.89^{\mathrm{b}}$ & $1.80 \pm 0.40^{\mathrm{b}}$ & $0.80 \pm 0.40^{\mathrm{b}}$ \\
\hline $\operatorname{Sim} 3$ & $55.60 \pm 2.87^{\mathrm{b}}$ & $39.60 \pm 2.87^{\mathrm{b}}$ & $3.20 \pm 0.75^{\mathrm{b}}$ & $1.40 \pm 0.80^{\mathrm{b}}$ & $0.20 \pm 0.40^{\mathrm{b}}$ \\
\hline Sim 15 & $55.80 \pm 3.19^{\mathrm{b}}$ & $41.00 \pm 2.61^{\mathrm{b}^{*}}$ & $2.20 \pm 0.98^{\mathrm{b}}$ & $0.60 \pm 0.80^{\mathrm{b}}$ & $0.40 \pm 0.49^{\mathrm{b}}$ \\
\hline Sim 30 & $52.60 \pm 1.74^{\mathrm{b}^{*}}$ & $42.20 \pm 1.72^{\mathrm{b}^{*}}$ & $3.40 \pm 0.80^{\mathrm{b}}$ & $1.40 \pm 1.02^{\mathrm{b}}$ & $0.40 \pm 0.80^{\mathrm{b}}$ \\
\hline Post 3 & $56.80 \pm 1.33^{\mathrm{b}}$ & $38.00 \pm 1.79^{\mathrm{b}}$ & $3.20 \pm 0.75^{\mathrm{b}}$ & $1.40 \pm 0.80^{\mathrm{b}}$ & $0.60 \pm 0.49^{\mathrm{b}}$ \\
\hline Post 15 & $56.80 \pm 2.23^{\mathrm{b}}$ & $39.00 \pm 1.79^{\mathrm{b}}$ & $2.40 \pm 0.49^{\mathrm{b}}$ & $1.20 \pm 0.40^{\mathrm{b}}$ & $0.60 \pm 0.80^{\mathrm{b}}$ \\
\hline Post 30 & $52.40 \pm 2.15^{\mathrm{b}^{*}}$ & $42.00 \pm 1.67^{b^{*}}$ & $3.20 \pm 0.75^{\mathrm{b}}$ & $2.00 \pm 1.26^{\mathrm{b}}$ & $0.40 \pm 0.49^{\mathrm{b}}$ \\
\hline
\end{tabular}

SE: standard error; C-: negative control group; $\mathrm{C}+$ : positive control group; AO: almond oil; PO: pulp oil; Pre: pretreatment; Sim: simultaneous treatment; Post: post-treatment. ${ }^{a}$ Compared with negative control; ${ }^{b}$ compared with

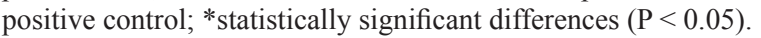

\section{Apoptosis}

Cyclophosphamide administration increased the frequency of apoptosis in the spleen, liver, and kidneys by 16.43-, 19-, and 25.25-fold, respectively. AO and PO treatment did not induce any change in the frequency of apoptosis compared with the negative control. Under all doses and protocols in the combined groups, the frequency of cyclophosphamide-induced apoptosis was decreased by up to 57.5-fold in the spleen, 114-fold in the liver, and 50.5-fold in the kidneys of the animals treated with AO and by 115-fold, 57-fold, and 101-fold in the same tissues of animals treated with PO (Table 7).

\section{DISCUSSION}

As cancer is one of the most common causes of death worldwide (Xie et al., 2013; WHO, 2015), the identification of medicinal and/or nutraceutical plants able to prevent the DNA damage associated with the onset of this disease has significant relevance to public health. Plants or parts of plants that can be consumed daily at a low cost and are able to prevent the development of tumors represent a significant category of functional foods at the present time. 


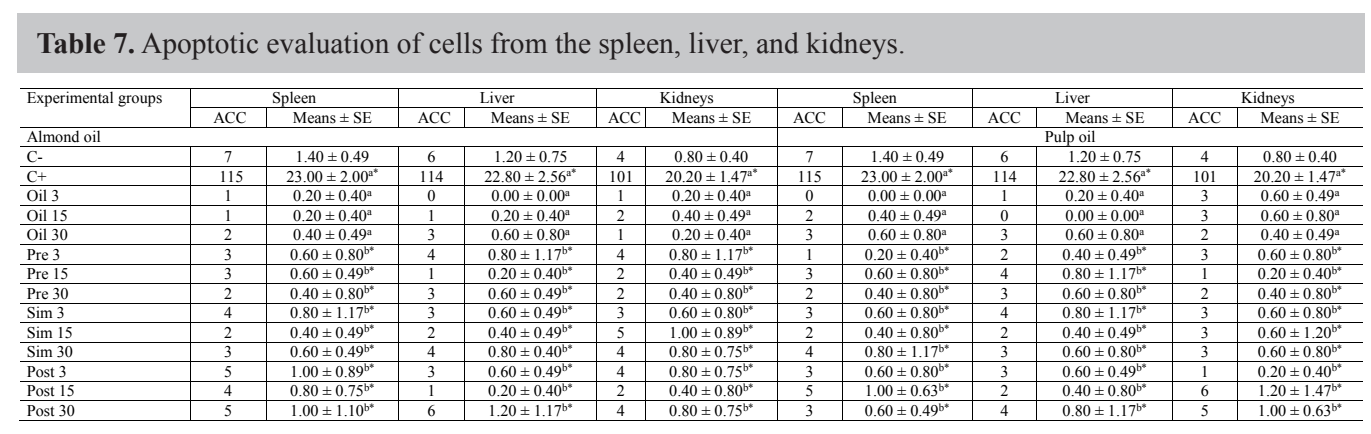

SE: standard error; ACC: apoptotic cell count; C-: negative control group; $\mathrm{C}+$ : positive control group; Pre: pretreatment; Sim: simultaneous treatment; Post: post-treatment. ${ }^{a}$ Compared with negative control; ${ }^{\mathrm{b}}$ compared with

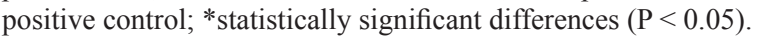

Functional foods or nutraceuticals are foods that help maintain health by reducing the risk of diseases through their abilities to modulate various body functions. Some of the main types of functional foods contain antioxidants that are able to inhibit or reduce the rate of oxidation reactions, such as those induced by reactive oxygen species that cause DNA damage. Therefore, antioxidants are considered to be inhibitors of carcinogenesis (Oliveira et al., 2006).

A. aculeata contains bioactive compounds that are important in human diets (Bressan et al., 2009), such as oleic acid, $\beta$-carotene, and tocopherols (Coimbra and Jorge, 2011). Therefore, this species has been subjected to genotoxicity and mutagenicity assays, in addition to immunomodulation and apoptosis tests, to assess properties of the plant that may reduce the development of cancer.

The results of the present study showed that AO and PO are nontoxic, as the experimental animals did not exhibit a significant change in weight that would indicate toxicity. Furthermore, the oils did not induce toxicogenetic damage, demonstrated by the fact that the frequency of comets and micronuclei did not increase at any of the tested doses. These findings confirm those reported in a study by Traesel et al. (2014), who assessed the toxicological profile of $A$. aculeata PO in acute and subacute toxicity assays. Their results showed that the median lethal dose $\left(\mathrm{LD}_{50}\right)$ was over $2000 \mathrm{mg} / \mathrm{kg}$ and that doses of 150-1000 $\mathrm{mg} / \mathrm{kg}$ did not alter hematologic, biochemical, or histologic parameters. The lack of toxicity was also reported by Traesel et al. (2015). This study established the $\mathrm{LD}_{50}$ with doses above $2000 \mathrm{mg} / \mathrm{kg}$ and found a lack of genotoxicity and mutagenicity for doses of $125-2000 \mathrm{mg} / \mathrm{kg}$.

The oils exhibited both antigenotoxic and antimutagenic activity, thus demonstrating their chemopreventive nature in all of the tested protocols. Comet frequency decreased at all of the tested doses. Only the lowest dose of AO in the pretreatment protocol (T3), the lowest dose of PO in the simultaneous treatment protocol (T1), and the lowest dose of PO in post-treatment protocol (T3) failed to exhibit chemopreventive activity in the micronucleus assay. The oils, which exhibit overall high \%DR values, are therefore considered relevant chemopreventive agents that can act by desmutagenesis and bioantimutagenesis.

Antimutagenesis is the type of desmutagenesis that occurs when compounds are shown to hinder the action of genotoxic or mutagenic agents in tests, mainly by adsorption (Kada et al., 1982). These compounds mainly act in the extracellular compartment. In turn, 
bioantimutagenesis refers to increases in the fidelity of enzymes involved in DNA repair and replication by promoting error-free repair or inhibiting certain low-fidelity repair systems. Thus, this process takes place in the intracellular compartment (Kada and Shimoi, 1987; Oliveira et al., 2006, 2007).

In vivo experiments reported in the literature indicate that simultaneous treatment assesses both desmutagenesis and bioantimutagenesis, while pretreatment assesses the desmutagenic mode of action and post-treatment assesses the bioantimutagenic mode of action. The administration route and time required for absorption of the tested foods or compounds should be taken into consideration (Primo et al., 2010; Pesarini et al., 2014). The present study employed protocols recommended in the literature to classify the mode of action of the $A$. aculeata oils, thus reporting these modes of action in the literature in a pioneering manner.

In addition to the aforementioned modes of action, reports in the literature indicate that antimutagenesis is directly associated with spleen phagocytosis events. In general, the induction of DNA damage (demonstrated by an elevated frequency of comets and micronuclei) is directly correlated with increased spleen phagocytic activity (Ishii et al., 2011; Gonçalves et al., 2014). Thus, this increased phagocytic activity is another potential means of clearing damaged cells, possibly indicating a new mode of action and/or behavior of the body to eliminate cells with genetic abnormalities. This way of eliminating cells would be important because there is a close relationship between the development of cancer and mutagenesis (Loureiro et al., 2002).

The present study shows that the tested antitumor agent and the oils, at the lowest and the highest doses applied, are able to stimulate spleen phagocytic activity. The significant increase in spleen phagocytic activity when the antitumor agent was applied might account for the increase in the number of cells with DNA damage that were measured by the comet and micronucleus assays. However, spleen phagocytic activity is increased without an increase in the number of cells with DNA damage when the oils were administered, since the oils do not exhibit toxicogenetic activity (neither genotoxicity nor mutagenicity). This finding suggests that the increase in spleen phagocytic activity might be mediated by immunomodulating mechanisms, rather than only being a response to genotoxic and mutagenic damage leading to an increase of the number of active macrophages in the spleen (Ishii et al., 2011; David et al., 2014; Fedel-Miyasato et al., 2014b; Gonçalves et al., 2014). When cyclophosphamide was combined with the oils using various doses and protocols, the levels of spleen phagocytic activity were intermediate between the levels exhibited by the groups treated with the oils alone and the group treated only with cyclophosphamide. Together with the high \%DR values obtained, these intermediate levels suggest that the main modes of the antimutagenic action of the oils are desmutagenesis and bioantimutagenesis and that the reduction in the number of circulating micronucleated cells is not due to increased spleen activity.

No relevant changes in the differential blood count were observed. This finding corroborates previous reports of low immunomodulatory activity of the tested oils under the present design.

When administered alone, the oils did not induce apoptosis in the spleen, liver, or kidneys. This finding supports the aforementioned claims regarding the lack of toxicity of the oils. In the combined protocols, the frequency of apoptosis in all three organs was significantly lower in the oil treatment groups than in the positive control. This finding suggests that the oils exhibit high anti-apoptotic activity. These data, together with the high \%DR values obtained 
in the post-treatment protocol, provide confirmation of the bioantimutagenic mode of action. Reduced apoptosis implies that the genetic damage induced by the antitumor agent was repaired before it could accumulate to extent that cells became unviable and apoptosis was triggered. Similarly, the high \%DR values observed under the pretreatment protocols suggest that the oils exhibited desmutagenic action, specifically through inhibiting the mutagenic action of cyclophosphamide (Oliveira et al., 2006). The results of simultaneous treatment do not indicate which antimutagenic mechanism occurred, but they support the interpretation of both aforementioned modes of action.

Similar results were reported by Oliveira et al. (2007), who found that $\beta$-glucan, an important antioxidant agent, exhibited simultaneous antimutagenic and anti-apoptotic activities. The authors described the desmutagenic and bioantimutagenic modes of action of $\beta$-glucan in CHO-K1 cells. They found that the bioantimutagenic action was less efficient. The authors repeated the tests with repair-deficient (xrs-5) CHO cells to confirm the bioantimutagenesis. These results revealed an absence of chemopreventive activity (antimutagenesis) and an increase of the frequency of apoptosis, which occurred because of the absence of an efficient repair system in this cell line.

We could infer that the products tested in this study possess the same bioantimutagenic action demonstrated by Oliveira et al. (2007) because $\beta$-glucan is an antioxidant and $A$. aculeata oils also contain antioxidant compounds (Coimbra and Jorge, 2011). Cyclophosphamide is a DNA alkylating agent with a considerable capacity to form intermediate compounds with free radicals that induce adverse effects in the body, such as the late formation of secondary tumors (Laurence et al., 2012). According to Weijl et al. (1998), these effects might be minimized through the concomitant administration of chemopreventive agents with antioxidant action, as anticancer drugs do not rely on free radical formation to kill the tumor cells. Therefore, antioxidants would not interfere with the action of the antineoplastic agents. However, we found that damage reduction was also high in the simultaneous treatment protocols, indicating that the oils might act via pathways other than their inferred antioxidant action. In this context, it is prudent to note that the oils should not be used as adjuvants during treatment with cyclophosphamide because they inhibit its genotoxic and mutagenic actions.

The results of the present study suggest that the oils of $A$. aculeata pulp and almond might represent functional foods with chemopreventive properties. Thus, they exhibit nutraceutical potential for cancer prevention. However, they are not adequate as sources for adjuvants to chemotherapeutic agents, particularly cyclophosphamide, because they are able to reduce mutagenic and apoptotic efficiency of this agent.

\section{Conflicts of interest}

The authors declare no conflict of interest.

\section{ACKNOWLEDGMENTS}

Research funded by FUNDECT.

\section{REFERENCES}

Bachur JA, Garcia SB, Vannucchi H, Jordao AA, et al. (2007). Anti-oxidative systems in rat skeletal muscle after acute physical exercise. Appl. Physiol. Nutr. Metab. 32: 190-196. http://dx.doi.org/10.1139/h06-078 
Baek SJ, McEntee MF and Legendre AM (2009). Review paper: Cancer chemopreventive compounds and canine cancer. Vet. Pathol. 46: 576-588. http://dx.doi.org/10.1354/vp.08-VP-0238-B-REV

Bressan J, Hermsdorff HHM, Zulet MA and Martínez JA (2009). [Hormonal and inflammatory impact of different dietetic composition: emphasis on dietary patterns and specific dietary factors]. Arq. Bras. Endocrinol. Metabol. 53: 572-581. http://dx.doi.org/10.1590/S0004-27302009000500010

Coimbra MC and Jorge N (2011). Proximate composition of guariroba (Syagrus oleracea), jerivá (Syagrus romanzoffiana) and macaúba (Acrocomia aculeata) palm fruits. Food Res. Int. 44: 2139-2142. http://dx.doi.org/10.1016/j. foodres.2011.03.032

David Nd, Mauro MdeO, Gonçalves CA, Pesarini JR, et al. (2014). Gochnatia polymorpha ssp. floccosa: bioprospecting of an anti-inflammatory phytotherapy for use during pregnancy. J. Ethnopharmacol. 154: 370-379. http://dx.doi. org/10.1016/j.jep.2014.04.005

Fedel-Miyasato LE, Formagio AS, Auharek SA, Kassuya CA, et al. (2014a). Antigenotoxic and antimutagenic effects of Schinus terebinthifolius Raddi in Allium cepa and Swiss mice: a comparative study. Genet. Mol. Res. 13: 3411-3425. http://dx.doi.org/10.4238/2014.April.30.2

Fedel-Miyasato LE, Kassuya CA, Auharek SA, Formagio ASN, et al. (2014b). Evaluation of anti-inflammatory, immunomodulatory, chemopreventive and wound healing potentials from Schinus terebinthifolius methanolic extract. Ver. Bras. Farmacog 24: 565-575. http://dx.doi.org/10.1016/j.bjp.2014.08.004

Gonçalves CA, Silva NL, Mauro MO, David N, et al. (2014). Evaluation of mutagenic, teratogenic, and immunomodulatory effects of Annona nutans hydromethanolic fraction on pregnant mice. Genet. Mol. Res. 13: 4392-4405. http://dx.doi. org/10.4238/2014.June. 11.3

Ishii PL, Prado CK, Mauro Mde O, Carreira CM, et al. (2011). Evaluation of Agaricus blazei in vivo for antigenotoxic, anticarcinogenic, phagocytic and immunomodulatory activities. Regul. Toxicol. Pharmacol. 59: 412-422. http:// dx.doi.org/10.1016/j.yrtph.2011.01.004

Kada T and Shimoi K (1987). Desmutagens and bio-antimutagens--their modes of action. BioEssays 7: 113-116. http:// dx.doi.org/10.1002/bies.950070305

Kada T, Inoue T and Namiki N (1982). Environmental desmutagens and antimutagens. In: Klekowski EJ, Environmental Mutagenesis and Plant Biology, Praeger, New York.

Lanes ÉC, Motoike SY, Kuki KN, Nick C, et al. (2015). Molecular characterization and population structure of the macaw palm, Acrocomia aculeata (Arecaceae), ex situ germplasm collection using microsatellites markers. J. Hered. 106: 102-112. http://dx.doi.org/10.1093/jhered/esu073

Laurence L, Brunton D, Björn CK and Bruce AC (2012). As Bases Farmacológicas da Terapêutica. 12th edn. ARTMED Publisher, Rio de Janeiro.

Lescano CH, Iwamoto RD, Sanjinez-Argandoña EJ and Kassuya CA (2015). Diuretic and anti-inflammatory activities of the microencapsulated Acrocomia aculeata (Arecaceae) oil on Wistar rats. J. Med. Food 18: 656-662. http://dx.doi. org/10.1089/jmf.2014.0077

Lima ES, Felfili JM, Marimon BS and Scariot A (2003). Diversidade, estrutura e distribuição espacial de palmeiras em um cerrado sensu stricto no Brasil Central - DF. Ver. Bras. Bot. 26: 361-370. http://dx.doi.org/10.1590/S010084042003000300009

Lorenzi GMAC, Negrelle RRB and Zaniolo SR (2006). Acrocomia aculeata (Jacq.) Lodd. ex Mart. - Arecaceae: bases para o extrativismo sustentável. Doctoral thesis, Setor de Ciências Agrárias, Universidade Federal do Paraná, Curitiba.

Loureiro APM, Mascio PD and Medeiros MHG (2002). Exocyclic DNA adducts: implications in mutagenesis and carcinogenesis. Quim. Nova 25: 777-793. http://dx.doi.org/10.1590/S0100-40422002000500014

Maluf SW and Erdtmann B (2003). In: Biomonitorização do dano genético em humanos. Genética Toxicológica, Editora Alcance, Porto Alegre.

Mantovani MS, Bellini MF, Angeli JP, Oliveira RJ, et al. (2008). $\beta$-Glucans in promoting health: prevention against mutation and cancer. Mutat. Res. 658: 154-161. http://dx.doi.org/10.1016/j.mrrev.2007.07.002

Navarro SD, Beatriz A, Meza A, Pesarini JR, et al. (2014). A new synthetic resorcinolic lipid 3-heptyl-3,4,6-trimethoxy$3 \mathrm{H}$-isobenzofuran-1-one: evaluation of toxicology and ability to potentiate the mutagenic and apoptotic effects of cyclophosphamide. Eur. J. Med. Chem. 75: 132-142. http://dx.doi.org/10.1016/j.ejmech.2014.01.057

Oetterer M, Regitando-D'arce MAB and Spoto MHF (2006). In: Fundamentos de ciência e tecnologia de alimentos. Editora Manole Ltda., Barueri.

Oliveira RJ, Ribeiro LR, da Silva AF, Matuo R, et al. (2006). Evaluation of antimutagenic activity and mechanisms of action of $\beta$-glucan from barley, in CHO-k1 and HTC cell lines using the micronucleus test. Toxicol. In Vitro 20: 1225-1233. http://dx.doi.org/10.1016/j.tiv.2006.04.001

Oliveira RJ, Matuo R, da Silva AF, Matiazi HJ, et al. (2007). Protective effect of $\beta$-glucan extracted from Saccharomyces 
cerevisiae, against DNA damage and cytotoxicity in wild-type (k1) and repair-deficient (xrs5) CHO cells. Toxicol. In Vitro 21: 41-52. http://dx.doi.org/10.1016/j.tiv.2006.07.018

Pesarini JR, Victorelli SG, Vicentini AP, Ferreira LK, et al. (2014). Antigenotoxic and antimutagenic effects of glutamine supplementation on mice treated with cisplatin. Genet. Mol. Res. 13: 4820-4830. http://dx.doi.org/10.4238/2014. July.2.11

Primo MS, Calliari CM, Castro-Gomez RJH, Mauro MO, et al. (2010). Assessment of mutagenicity and antimutagenicity of a biopolymer extracted from the microorganism Agrobacterium radiobacter in mice. Rev. Bras. Farm. 20: 340347. http://dx.doi.org/10.1590/S0102-695X2010000300009

Sies H(1993). Strategies of antioxidant defense. Eur. J. Biochem. 215:213-219. http://dx.doi.org/10.1111/j.1432-1033.1993. tb18025.x

Sosnowska J and Balslev H (2008). American palms used for medicine, in the ethnobotanical and pharmacological publications. Ver. Peru Biol. 5: 143-146.

Traesel GK, de Souza JC, de Barros AL, Souza MA, et al. (2014). Acute and subacute (28 days) oral toxicity assessment of the oil extracted from Acrocomia aculeata pulp in rats. Food Chem. Toxicol. 74: 320-325. http://dx.doi.org/10.1016/j. fct.2014.10.026

Traesel GK, Castro LHA, Silva PVB, Muzzi RM, et al. (2015). Assessment of the cytotoxic, genotoxic, and mutagenic potential of Acrocomia aculeata in rats. Genet. Mol. Res. 14: 585-596. http://dx.doi.org/10.4238/2015.January.26.13

Weijl NI, Hopman GD, Wipkink-Bakker A, Lentjes EG, et al. (1998). Cisplatin combination chemotherapy induces a fall in plasma antioxidants of cancer patients. Ann. Oncol. 9: 1331-1337. http://dx.doi.org/10.1023/A:1008407014084

WHO - World Health Organization (2015). Fact sheet N²97. http://www.who.int/mediacentre/factsheets/fs297/en/. Accessed May 28, 2015.

Xie JH, Liu X, Shen MY, Nie SP, et al. (2013). Purification, physicochemical characterisation and anticancer activity of a polysaccharide from Cyclocarya paliurus leaves. Food Chem. 136: 1453-1460. http://dx.doi.org/10.1016/j. foodchem.2012.09.078 